\title{
Twenty-five years of nano-bio-materials: have we revolutionized healthcare?
}

\author{
"Nanomedicine may not have completely \\ revolutionized healthcare as yet, but it is on the way."
}

First draft submitted: 21 March 2016; Accepted for publication: 28 March 2016; Published online: 19 April 2016

Keywords: Healthcare $\bullet$ nano-biomaterials $\bullet$ nano-medicine $\bullet$ regenerative medicine $\bullet$ tissue engineering

The term 'nano' was coined back in 1990's to denote anything novel, progressive and futuristic. In sciences, the term 'nano' is a unit prefix that indicates one billionth $\left(10^{-9}\right)$, a dimension, for example, that is larger than 'pico' $\left(10^{-12}\right)$ and smaller than 'micro' $\left(10^{-6}\right)$. In 1990s and up to middle 2000s, a material was considered as 'nano scale' at dimensions smaller than $1 \mu \mathrm{m}$. Nowadays, as the science and technology has progressed, in the physical sciences space, the term 'nano' refers to materials with dimensionality smaller than $100 \mathrm{~nm}$, while in the biomedicine field 'nano' is used to describe any object with dimensions between 250 and $750 \mathrm{~nm}$.

Nano-biomaterials, nano-medicine and nano-bio-interface are terms used interchangeably to denote tools, technologies and discoveries of nanotechnology that are utilized in medicine. The supremacy of nano-devices in medicine is founded on the fact that this scale closely imitates the small dimensionality of native cells and extracellular matric component and operates on the same small scale as several functions in the body. Thus, when we started developing nano-bio-materials, almost 25 years ago, we hypothesized that nano-scale devices would be more physiologically relevant than their macro-scale counterparts. Our aspiration was that these small devices would revolutionize healthcare with their massive impact. Where are we now?

The global nanomedicine market was valued at US $\$ 248$ billion in 2014 and is projected to grow at a compound annual growth rate of $16.3 \%$ until 2019, reaching value of US\$ 528 billion [1]. This is not surprising given that in Europe alone over $€ 650$ million were invested in nano-bio-related projects during the FP7 round of calls [EC, Personal Communication]. This staggering funding has resulted in exponential growth in the number of peer-reviewed publications (Figure 1). Proportional is the situation in commercial and clinical space as evidenced by 1756 patents (source: European Patent Office; Term Searched: 'nano' in title and 'medicine' in Title or Abstract) and over 116 currently registered clinical trials (source: clinicaltrials.gov; Term searched: 'nano'). The obvious question is what has really been achieved with all of this funding?

Advances in engineering have made available numerous top-down (e.g., imprinting lithography) and bottom-up (e.g., electrospinning) nano-fabrication technologies that are at the forefront of scientific and technological research and innovation for the development of two- and three- dimensional biomimetic structures. Two-dimensional imprinted devices have been used extensively to maintain phenotype fidelity of permanently differentiated cells or to precisely control stem cell lineage commitment during in vitro expansion [2-4]. The potential of three-dimensional electro-spun nanofibrous scaffolds as drug delivery vehicles and as means to direct neotissue formation has been well established [5-7]. Nanocarriers are being developed for sus-

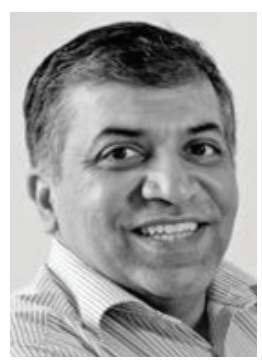

Abhay Pandit

Science Foundation Ireland (SFI) Centre for Research in Medical Devices (CÚRAM), Biomedical Sciences Building, National University of Ireland Galway (NUI Galway), Galway, Ireland

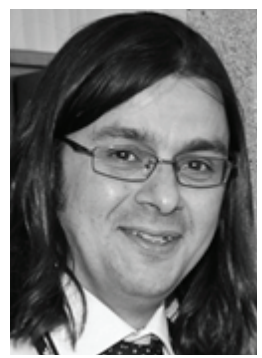

Dimitrios I Zeugolis

Author for correspondence:

Science Foundation Ireland (SFI) Centre for Research in Medical Devices (CÚRAM), Biomedical Sciences Building, National University of Ireland Galway (NUI Galway), Galway, Ireland and

Regenerative, Modular \& Developmental Engineering Laboratory (REMODEL), Biomedical Sciences Building, National University of Ireland Galway (NUI

Galway), Galway, Ireland

Tel.: +353091493166

Fax: +353091563991

dimitrios.zeugolis@nuigalway.ie

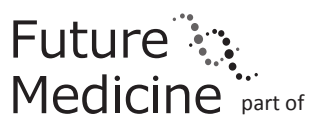




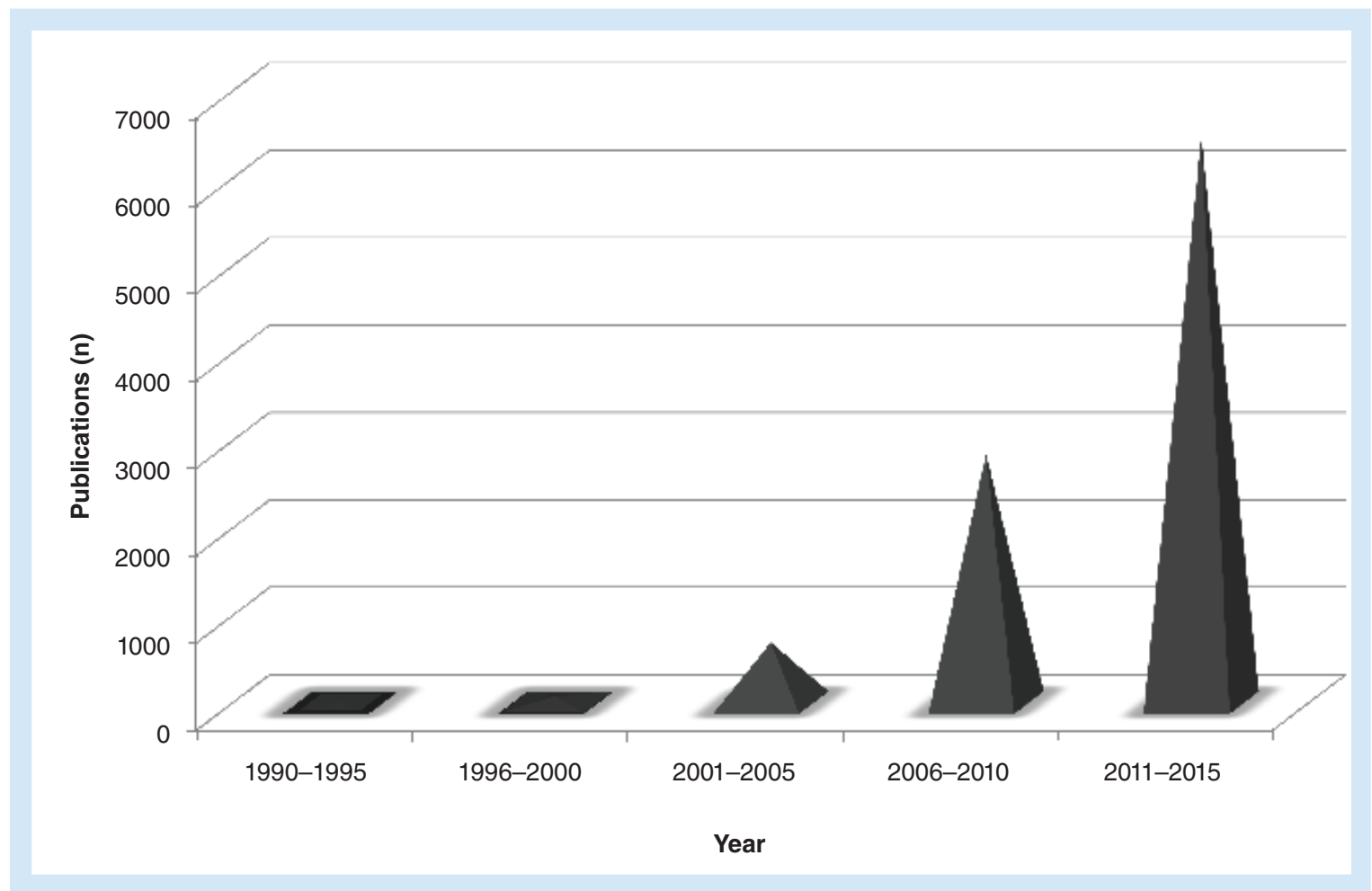

Figure 1. Exponential increase in the number of peer-reviewed publications in the field of nanomedicine. Source: PubMed; Term searched: 'nano' in title only.

tained and localized delivery of therapeutics and bioactive molecules, and have found several applications in biomedicine, including cancer [8-10], Alzheimer's [11], Parkinson's [12] and HIV [13]. Significant strides have also been achieved in imaging space with nano-particles [1416]. Unfortunately, limitations have also been reported as it would have been expected with any new technology. For example, the clinical potential of imprinted substrates has been questioned in light of recent preclinical evidence $[17,18]$, while nano-toxicity has raised concerns with respect to the safety of such materials [19-21].

In this special issue, we discuss various advancements in nano-fabrication technologies (e.g., twophoton polymerization [22], imprinting and electrospinning [23]) and nano-materials (e.g., liposomes [24], nanoscale bioactive glass [25], magnetically actuated biomaterials [26], nanoparticles [27-31] and electrospun fibers $[32,33]$ ) and their influence in regenerative medi-

\section{References}

1 BCCResearch. Nanotechnology in medical applications: the global market (HLC069C) (2015).

www.bccresearch.com

2 Dalby M, Gadegaard N, Oreffo R. Harnessing nanotopography and integrin-matrix interactions to influence stem cell fate. Nat. Mater. 13(6), 558-569 (2014). cine applications, such as cell programming [34], cell fate [35] and drug delivery [36]. Nanomedicine may not have completely revolutionized healthcare as yet, but it is on the way.

\section{Financial \& competing interests disclosure}

This publication has supported from the Health Research Board (grant agreement number: HRA_POR/2011/84) and the Science Foundation Ireland and the European Regional Development Fund (grant agreement number: 13/RC/2073). The authors have no relevant affiliations or financial involvement with any organization or entity with a financial interest in or financial conflict with the subject matter or materials discussed in the manuscript. This includes employment, consultancies, honoraria, stock ownership or options, expert testimony, grants or patents received or pending, or royalties.

No writing assistance was utilized in the production of this manuscript.

3 McMurray R, Gadegaard N, Tsimbouri P et al. Nanoscale surfaces for the long-term maintenance of mesenchymal stem cell phenotype and multipotency. Nat. Mater. 10(8), 637-644 (2011).

4 Dalby M, Gadegaard N, Tare R et al. The control of human mesenchymal cell differentiation using nanoscale symmetry and disorder. Nat. Mater. 6(12), 997-1003 (2007). 
5 Ingavle G, Leach J. Advancements in electrospinning of polymeric nanofibrous scaffolds for tissue engineering. Tissue Eng. Part. B Rev. 20(4), 277-293 (2014).

6 Hu X, Liu S, Zhou G, Huang Y, Xie Z, Jing X. Electrospinning of polymeric nanofibers for drug delivery applications. J. Control. Release 185 12-21 (2014).

7 Fuller K, Pandit A, Zeugolis D. The multifaceted potential of electro-spinning in regenerative medicine. Pharm. Nanotechnol. 2(1), 23-34 (2014).

8 Shao K, Singha S, Clemente-Casares X, Tsai S, Yang Y, Santamaria P. Nanoparticle-based immunotherapy for cancer. ACS Nano 9(1), 16-30 (2015).

9 Kemp J, Shim M, Heo C, Kwon Y. "Combo" nanomedicine: Co-delivery of multi-modal therapeutics for efficient, targeted, and safe cancer therapy. Adv. Drug Deliv. Rev. 98, 3-18 (2016).

Wicki A, Witzigmann D, Balasubramanian V, Huwyler J. Nanomedicine in cancer therapy: challenges, opportunities, and clinical applications. J. Control. Release 200, 138-157 (2015).

11 Gregori M, Masserini M, Mancini S. Nanomedicine for the treatment of Alzheimer's disease. Nanomedicine (Lond.) 10 (7), 1203-1218 (2015).

12 Leyva-Gómez G, Cortés H, Magaña J, Leyva-García N, Quintanar-Guerrero D, Florán B. Nanoparticle technology for treatment of Parkinson's disease: the role of surface phenomena in reaching the brain. Drug Discov. Today 20(7), 824-837 (2015).

13 Neves J, Nunes R, Rodrigues F, Sarmento B. Nanomedicine in the development of anti-HIV microbicides. Adv Drug Deliv Rev. doi:10.1016/j.addr.2016.01.017 (2016) (Epub ahead of print).

14 Schäferling M. Nanoparticle-based luminescent probes for intracellular sensing and imaging of $\mathrm{pH}$. Wiley Interdiscip. Rev. Nanomed. Nanobiotechnol. doi:10.1002/wnan.1366 (2016) (Epub ahead of print).

15 Shin T, Choi Y, Kim S, Cheon J. Recent advances in magnetic nanoparticle-based multi-modal imaging. Chem. Soc. Rev. 44(14), 4501-4516 (2015).

16 Garcia J, Tang T, Louie A. Nanoparticle-based multimodal PET/MRI probes. Nanomedicine (Lond.) 10 (8), 1343-1359 (2015).

17 English A, Azeem A, Spanoudes K et al. Substrate topography: a valuable in vitro tool, but a clinical red herring for in vivo tenogenesis. Acta Biomater. 27, 3-12 (2015).

18 Azeem A, English A, Kumar P et al. The influence of anisotropic nano- to micro-topography on in vitro and in vivo osteogenesis. Nanomedicine (Lond.) 10(5), 693-711 (2015).

19 Tortiglione C. The heritable effects of nanotoxicity. Nanomedicine (Lond.) 9(18), 2829-2841 (2014).

20 Celá P, Veselá B, Matalová E, VeČeŘa Z, Buchtová M. Embryonic toxicity of nanoparticles. Cells Tissues Organs 199(1), 1-23 (2014).

21 Xue H, Liu S, Wong H. Nanotoxicity: a key obstacle to clinical translation of siRNA-based nanomedicine. Nanomedicine (Lond.) 9(2), 295-312 (2014).

22 Timashev P, Kuznetsova D, Koroleva A et al. Novel biodegradable star-shaped polylactide scaffolds for bone regeneration fabricated by two-photon polymerization. Nanomedicine (Lond.) 11(9), 1041-1053 (2016).

23 Biggs M, Pandit A, Zeugolis D. Two-dimensional imprinted substrates and three-dimensional electro-spun scaffolds revolutionise biomedicine. Nanomedicine (Lond.) 11(9), 989-992 (2016).

24 Wang G, Nguyen T, Huang L, Gauthier M, Yang G, Wang Q. Recent advances in liposome surface modification for oral drug delivery. Nanomedicine (Lond.) 11(9), 1169-1185 (2016).

25 Detsch R, Rübner M, Strissel P et al. Nanoscaled bioactive glass activates osteoclastic differentiation of RAW 264.7 cells. Nanomedicine (Lond.) 11(9), 1093-1105 (2016).

26 Santos L, Silva M, Goncalves A, Pesqueira T, Rodrigues M, Gomes M. In vitro and in vivo assessment of magnetically actuated biomaterials. Nanomedicine (Lond.) 11(9), 1107-1122 (2016).

27 Detappe A, Lux F, Tillement O. Pushing radiation therapy limitations with theranostic nanoparticles. Nanomedicine (Lond.) 11(9), 997-999 (2016).

28 Wyss P, Lamichhane S, Rauber M, Thomann R, Krämer $\mathrm{K}$, Shastri V. Tripod USPIONs with high aspect ratio show enhanced T2 relaxation and cytocompatibility. Nanomedicine (Lond.) 11(9), 1017-1030 (2016).

29 Grinstaff M, Herrera V, Colby A et al. Evaluation of expansile nanoparticle tumor localization and efficacy in a cancer stem cell-derived model of pancreatic peritoneal carcinomatosis. Nanomedicine (Lond.) 11(9), 1001-1015 (2016).

30 Valencia-Serna J, Chevallier P, Remant-Bahadur K, Laroche G, Uludag H. Fibronectin-modified surfaces for evaluating the influence of cell adhesion on sensitivity of leukemic cells to siRNA nanoparticles. Nanomedicine (Lond.) 11(9), 1123-1138 (2016).

31 Bongio M, Lopa S, Gilardi M, Bersini S, Moretti M. A 3D vascularized bone remodeling model combining osteoblasts and osteoclasts in a $\mathrm{CaP}$ nanoparticles-enriched matrix. Nanomedicine (Lond.) 11(9), 1073-1091 (2016).

32 Wang W, He J, Feng B et al. Aligned nanofibers direct human dermal fibroblasts to tenogenic phenotype in vitro and enhance tendon regeneration in vivo. Nanomedicine (Lond.) 11(9), 1055-1072 (2016).

33 Fuller K, Gaspar D, Delgado L, Pandit A, Zeugolis D. The influence of porosity and pore shape on biophysical, biochemical and biological properties of electro-spun nanofibrous meshes. Nanomedicine (Lond.) 11(9), 1031-1040 (2016).

34 Hsieh C, Alberton P, Loffredo-Verde E et al. Scaffold-free scleraxis-programmed tendon progenitors aid in enhanced repair of full-size Achilles tendon rupture. Nanomedicine (Lond.) 11(9), 1153-1167 (2016).

35 Ventre M, Netti P. Nanoengineered materials to control cell fate. Nanomedicine (Lond.) 11(9), 993-996 (2016).

36 Camacho K, Menegatti S, Mitragotri S. Low-molecularweight polymer-drug conjugates for synergistic anticancer activity of camptothecin and doxorubicin combinations. Nanomedicine (Lond.) 11(9), 1139-1151 (2016). 